\title{
Innovation in Mathematics Education through Lesson Study: Challenges to STEM on Statistics and Electricity Saving
}

\author{
Riyanta \& Ika Wulandari \\ SMK N 2 Wonosari, Yogyakarta, Indonesia \\ ts_riyanto@yahoo.com_ariensuharyono@yahoo.co.id
}

\begin{abstract}
This collaborative research aims to provide necessary scientific and practical knowledge on statistics and electricity saving topics through integration of energy efficiency into vocational schools' mathematics curriculum. The paper reports on how the teachers in a lesson study group developed teaching and learning models on statistics integrated with electricity saving. The implementation processes of this learning model started with data collection, continued with data processing, data presentation, and data analysis of the electricity billing payment of the students' houses. Through this learning process, the students were expected to be more aware in saving electricity and using energy wiser. The analyses were done qualitatively using triangulation including combining documents, observations, photographs, and videos. The findings revealed that this learning model sharpened the students' ability around reasoning, processing, presenting and analyzing the data from contextual problems. Students could also define the factors affecting the electricity used, and then identify the ways to save energy. Further, the students created a simple video and poster for a saving electricity campaign at school, home, and social media. While the results are interesting and encouraging and provide some promising directions, they are not a proof and a much larger study would be needed to determine if the results are due to the approach or due to the teachers' enthusiasm, novelty effect or what is known as the Hawthorne Effect.
\end{abstract}

Keywords: thematic, contextual learning, innovation, STEM, school mathematics, research, lesson study

\section{Introduction}

Science and mathematics teaching emphasizing the development of reasoning, logical thinking, and scientific ability is very important in preparing the younger generation to deal with the problems of daily life and to address successfully the challenges of globalization. The globalization era is characterized by the rapid technology development, and the increased energy demands in the world. On the one hand, the development of information technology is very helpful to various life aspects. However, when it is not utilized wisely, its presence will affect negatively the future of the younger generation. On the other hand, the increased energy demands on a global scale is an inevitable problem. The energy demand in the economic and industrial sectors is still met by fossil energy that will be depleted in the future. Meanwhile, renewing it will take millions of years. This presents natural disasters, energy and economic that must be faced later by the younger generation.

The increased energy demand on a global scale can be seen in Figure 1. The diagram from Ishii (2016) shows us the comparison between APEC (red) and Non-APEC (grey) economies regarding their energy demands. The Energy Ministerial Meeting 2014 addressed some issues as follows: (1) the world's energy supply and demand pattern has been changing, (2) the global energy demand continues to rise steadily, (3) the Asia-Pacific assumes a more prominent role as the center of world energy demand, and (4) at the same time, the political and 
economic environments together with fluctuations in the energy market, climate change, and public perception and acceptance will exert huge pressure on the energy policy making in the Asia-Pacific region. Moreover, energy costs are crucial to the competitiveness of energy intensive industries in the region (Beijing Declaration - Joining Hands towards Sustainable Energy Development in the Asia-Pacific Region, Energy Ministerial Meeting 2014). Thus, the globalization challenges require the present generation to think logically, creatively, innovatively, and skilfully using technology. Life success and sustainability in the future lies with the next generation. For these reasons it is important for education to use innovation to prepare the younger generation for such challenges and threats particularly related to energy efficiency.

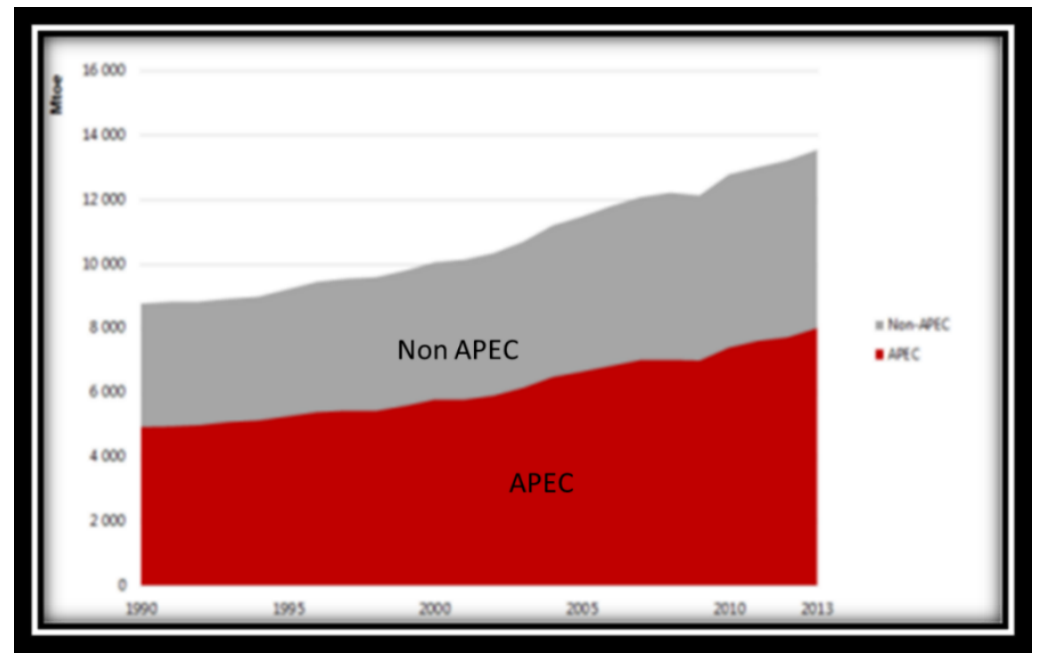

Figure 1. Global energy demand (Ishii, 2016)

Teachers through their contribution in education are very important in preparing the younger generations by equipping them with science skills, life competency, and character education. Care about natural and social environments and society should be developed in education. It is argued that global issues concerning natural disaster, energy crises, economic crises, and threats should be introduced earlier in education. It is also argued that the students should be accustomed to think critically and logically, to reason and to innovate in response to the various issues listed above. The National Council of Teachers of Mathematics (NCTM, 2000, p. 11) suggests that students must learn mathematics with understanding, actively building new knowledge from experience and prior knowledge. Meaningful learning should refer to standard process by emphasizing reasoning and sense making (NCTM, 2009, p. 5). This means that every learning process should be supported by infrastructures, learning media, and contextual issues. A learning process will be less meaningful if the learning media emphasizes only the procedural skills. The lesson will be easily forgotten by the students and potentially lead to the misconception and difficulty in learning process (Kilpatrick, Swafford, \& Findell, 2001). 
The integration of science, technology, engineering and mathematics (STEM) or integrated thematic learning is very possible to raise energy efficiency issues. In this lesson study research, STEM activity is carried out with an understanding that without practice in real life it is difficult for the students to understand the issues (Wang, Moore, Roehrig, \& Park, 2011). For that reasons, the writer is interested in making innovation in mathematic learning by raising electricity saving in STEM and involving the lesson study team established by SEAMEO Regional Center for QITEP in Mathematics (SEAQiM).

\section{Science, Technology, Engineering and Mathematics (STEM)}

The STEM content areas are taught as though they were one subject. Integration can be done with a minimum of two disciplines but is not limited to two disciplines. The lines indicate the various options in which integration could be achieved.

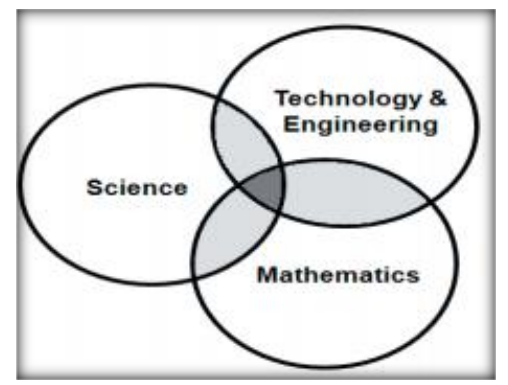

Figure 2. Integration approach to STEM education

Wang et al. (2011) explain interdisciplinary integration begins with a real-world problem. It incorporates cross-curricular content with critical thinking, problem-solving skills, and knowledge in order to reach a conclusion. Multidisciplinary integration asks students to link content from specific subjects, but interdisciplinary integration focuses students' attention on a problem and incorporates content and skills from a variety of fields. The real problem in this electricity saving statistics activity is whether the electricity usage in the student families tends to be above or below the mean electricity use of student families in one classroom over several months. The students are told to estimate its causes. In this problem, mathematics is integrated into physics related to topic on energy. Energy topic studied includes definitions, types of energy, renewable energy, and non-renewable energy. Meanwhile, the statistics involves describing and presenting data, displaying data in the form of appropriate tables, charts or plots, and communicating information of a data series through comparative analysis on various data displays. The students are allowed to use both the Excel ${ }^{\mathrm{TM}}$ program and a calculator to facilitate the calculation so that more time is spent on reasoning and analyzing data. As suggested by Afrial and Rohmah (2014), using Excel ${ }^{\mathrm{TM}}$ program can enhance understanding of content within a graphics presentation; it provides a visual representation of data that makes it easier to analyze. In addition, Excel ${ }^{\mathrm{TM}}$ reduces the difficulty of plotting data and allows students a means for interpreting the data. 
Sharing and growing together in a lesson study group is very beneficial and provides new experiences to the students, teachers and school where the research was conducted. Teachers, before joining this activity, have attempted to connect the learning material to energy efficiency theme. This activity helps open the teachers' insight in order to explore further and encourages them to share and collaborate with each other. They can be open to constructive critique and suggestions in accomplishing the developed learning plan. This activity gives the students more contextual experience during learning process. The students who usually are not thinking of saving energy become more careful and more motivated to use energy wisely. In addition, the students feel the power of mathematics in their daily life. This learning development is related to collecting, processing, displaying, and analyzing data from the student families' personal electricity payment receipt.

The objectives of the research through lesson study are generally to: (1) increase the awareness students on the issue of energy efficiency in real life, (2) facilitate students with the scientific and practical knowledge regarding energy efficiency and related skills to reduce or minimize the use of energy, (3) increase students' beliefs on the importance of mathematics, science, and technology and motivate them to improve their attitudes toward mathematics, science, and technology, and (4) increase students awareness, prediction and anticipation of energy efficiency.

\section{Method}

This research employed a descriptive qualitative method. The objective of research was to develop an integrated learning activity in STEM through lesson study. This research focused on the material of statistics related to energy efficiency.

The questions emerging among others are: (1) How to help students learn statistics related to energy efficiency meaningfully? (2) How to help students to learn statistics related to energy efficiency joyfully? (3) How to help students to learn to think? and (4) How to help students to learn statistics related to energy efficiency by and for themselves (collaborative and independent learners)?

Overall, the procedure of lesson study used was 'Plan-Do-See'. 'Plan' involves seeing a curriculum based on the theme of energy; choosing the material that matches the theme of energy; developing lesson plans; peer teaching; and revising the lesson plans. 'Do' covers scheduling; discussions with partner teachers as well as observers; implementation of the lesson plan 1; reflection; implementation of the lesson plan 2; reflection; implementation of the lesson plan 3; reflection; and collecting data. 'See' includes the reflection with observers from SEAQiM and teachers in SMK N 2 Wonosari; and evaluation. 
The research cycle used involved: (1) designing and developing learning activities, (2) peer teaching, (3) field experiment, (4) observation, (5) reflection, (6) reporting, and (7) dissemination.

\section{Results and Discussion}

Lesson study Activity was initiated with workshop on learning set development which was held in SEAQiM. After the learning set had been developed completely, it was continued with peer teaching, including presentation and teaching practice based on the set developed. This activity is conducted to elicit constructive critique, suggestion, and input to make the developed set better and ready to apply. The next stage was the implementation in the classroom. The authors, acted as the teachers, conducted the activity corresponding to the revised learning plan. Then, observation and reflection were assisted by SEAQiM experts. This activity is intended to evaluate and to analyze the results of classroom practice to be reported and disseminated later.

The mathematics learning was related to basic statistics involving describing and displaying data in the form of appropriate table, chart or plot to communicate information of data series through comparative analysis on varying data displays. After taking a pre-test, the students were asked to submit their families' electricity and water bills, and to record the fuel use for their personal motorcycle when going to and from school. In addition, the students were assigned to browse news broadcasts or articles related to energy efficiency. Those articles were beneficial to give insight into energy efficiency.
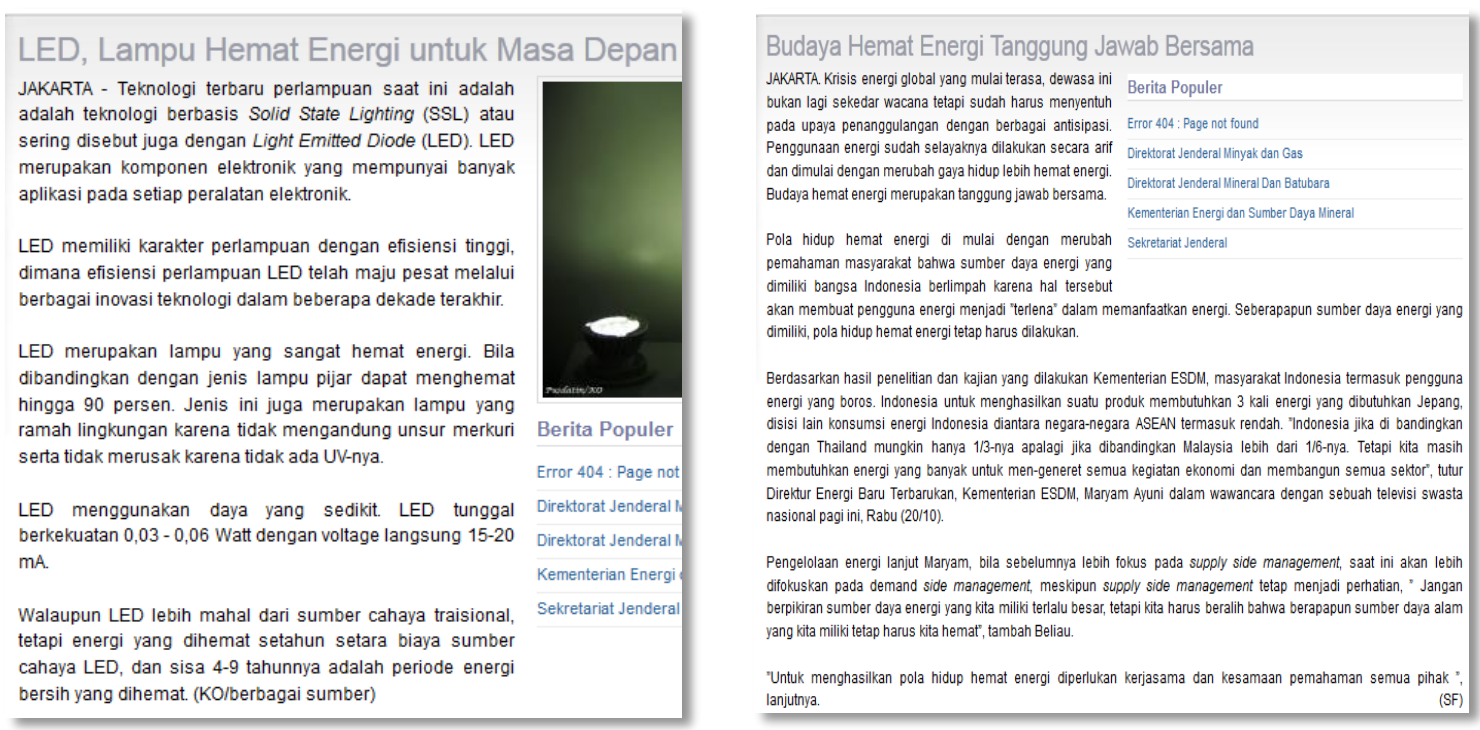

Figure 3. Sample articles browsed by students

In the first meeting, as an opening activity, a student is voluntarily asked to reveal his/her perspective/thinking about article/news on energy efficiency they obtain. Furthermore, 
the students were told to observe a set of electricity billings they carry with them. The teacher told them to recall the statistic material they had ever learnt in junior high school. Then, they were stimulated with the following questions: "What can be done to process and to display data of electricity billing set?" and "What can we analyze and conclude from the activity of processing and displaying the data of personal electricity billing?" Some students answered that the data can be ordered and displayed in the form of a table and chart. The data can also be analyzed and processed to see the mean, median, mode, highest data, lowest data, etc.

During the main activity, the teacher gave the students the freedom of displaying and analyzing the data of the electricity billing, and connecting it to information on energy efficiency. The students were allowed to use the Excel ${ }^{\mathrm{TM}}$ program, calculator, and other aids.

In the first meeting of $2 \times 45$ minutes duration: (1) the students discussed in their group how to collect, to process, to display, and to analyze the data of their family electricity payment receipt, (2) the students were allowed to count manually, or use a calculator, Excel ${ }^{\mathrm{TM}}$ and other programs/aids, and (3) the students presented their work voluntarily.
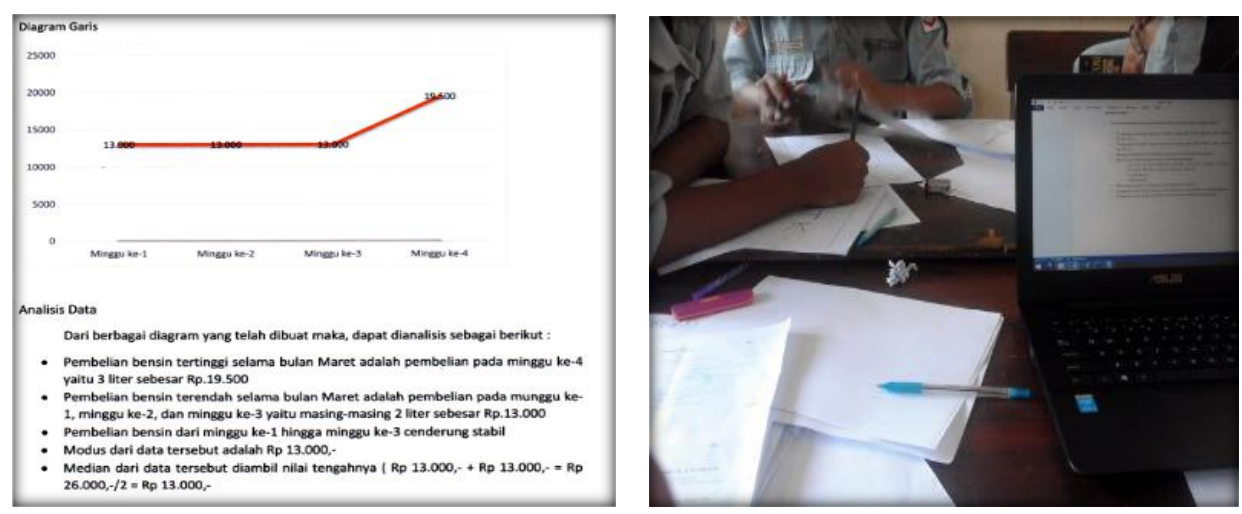

Figure 4. Documentation from the first meeting

In the second meeting of $2 \times 45$ minutes duration: (1) the students discussed in groups how to compare and to analyze the data of the mean monthly family electricity needs and the mean family electricity needs of entire class, (2) the students were allowed to count manually or to use calculator, Excel ${ }^{\mathrm{TM}}$, or other programs/aids, and (3) the students presented their work voluntarily.
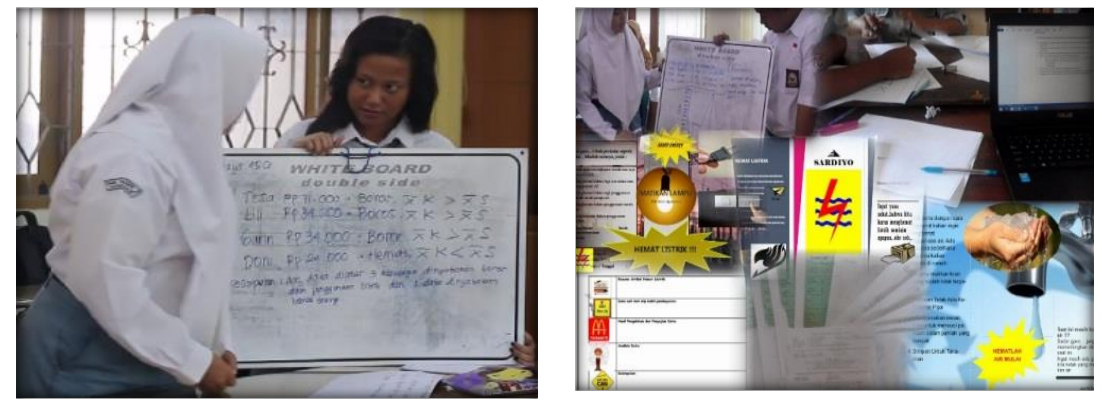

Figure 5. Documentation from the third meeting 
In the third meeting of duration $2 \times 45$ minutes: (1) the students made an electricity saving campaign in the classroom using posters, brochures and or simple videos which constituted the product of their group work at home, and (2) the students delivered their plan of the electricity saving campaign at home, school, and social media.

In the closing activity, the students gave critique, input, and suggestions (recommendations) to other groups and the teacher gave reinforcement (confirmation) and drew a conclusion along with the students from the statistics and the electricity saving related activity. The activity ended by facilitating the students to reveal the benefit of statistics with electricity saving theme.

After the learning activity had been completed, a post-test and reflection activity were conducted. The post-test questions were the same as the pre-test ones, related to energy efficiency in real life. From the data of the pre-test, it was found that beliefs and awareness of the students on the issue of energy efficiency in real life was 7.71 (medium), and increased to 10.32 (high) on the post-test. The percentage increase from pre-test to post-test was $33.9 \%$. The details of the analysis are presented in the Table 1.

Table 1 .

Percentage of Students Belief and Awareness on Energy Efficiency in Real Life

\begin{tabular}{clcc}
\hline Rubric & Notes & Pre-test & Post-test \\
\hline 1 & $\begin{array}{l}\text { To help increase the awareness of Indonesian students on the } \\
\text { issue of energy efficiency in real life }\end{array}$ & $62 \%$ & $67 \%$ \\
\hline 2 & $\begin{array}{l}\text { To help and facilitate Indonesian students with the scientific and } \\
\text { practical knowledge regarding energy efficiency and related skills } \\
\text { to reduce or minimize the use of energy }\end{array}$ & $66 \%$ & $66 \%$ \\
\hline 3 & $\begin{array}{l}\text { To help increase Indonesian students' beliefs on the importance } \\
\text { of mathematics, science, and technology that will motivate them } \\
\text { having good attitudes toward mathematics, science, and } \\
\text { technology }\end{array}$ & $79 \%$ & $98 \%$ \\
\hline 4 & $\begin{array}{l}\text { To help increase Indonesian students' beliefs on the importance } \\
\text { of mathematics, science, and technology that will motivate them } \\
\text { having good attitudes toward mathematics, science, and } \\
\text { technology }\end{array}$ & $24 \%$ & $73 \%$ \\
\hline
\end{tabular}

\section{Reflection}

One of the strengths of this research is that the theme of statistics is consistent with the Curriculum 2013 of old spectrum for the tenth grade of vocational school with topics including 'displaying data in the form of certain table and chart/plot which is consistent with the information to be communicated'. The students are expected to display the data in the form of tables and diagrams (chart), and to analyze and to communicate their representations. The contextual issue raised is electricity saving. The students were asked to process and to analyze the data of their families' electricity use. Learning activities emphasized reasoning and the contextual problem solving was more meaningful to the students, compared with an activity 
focusing only upon sharpening mathematic skill with drill and practice. In addition, this learning activity utilizes the technology the students have mastered, such as the Excel ${ }^{\mathrm{TM}}$ program or calculator, to process and to display data.

This learning activities also utilized the students' ability to prepare simple posters and videos. The students' ability of using technology should be directed and accustomed to develop the positive things. In this research, the students were told to prepare simple posters and videos for campaigning electricity saving in the classroom, school environment, and society, either directly or indirectly. The indirect campaign could be carried out using social media. Through this activity, the students are expected to be accustomed to using technology and social media wisely and positively.

In the learning process, there was an activity of analyzing the factors affecting the volume of energy use; it is very good for the students to reason and to reflect on daily activity in the student family related to habits and decisions in using energy. Through discussing and arguing corresponding to the students' experience, the students were expected to use energy wiser.

On the other hand, this research has some weaknesses as well, one of which is that learning was started with contextual problem, but the packaging of student worksheets still needed improvement to be more engaging. This will make learning more meaningful and joyful and invites the students to think and to be independent compared with previous statistic learning conducted by the author. In the beginning of learning, the discussion concerning energy should be conducted in a shorter time.

The teacher gave the stimulus question when starting the lesson: What can we do to process this data based on your previous experience? However the teacher did not need to emphasize or to direct the students to calculate immediately or to calculate the mean only. The students should be given time and discretion to determine what will be done. The teacher did not impose a limit or standard to conclude whether electricity use belongs to high or low category. The teacher should raise the error one group made in drawing a line chart and challenge them to use a deeper source of exploration. However, it is better for the entire group to present its work. Or if possible, presentation gallery can also be used to display and to discuss students' work.

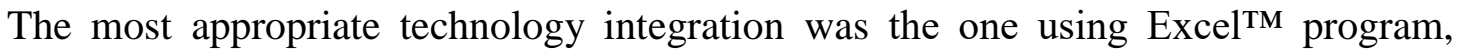
however in one activity it was not been utilized optimally. The teacher should position himself or herself or serve as a facilitator. The closing activity should emphasize what can be developed after learning this material. 


\section{Conclusion and Recommendation}

This lesson study activity is really beneficial to the students, teachers, and schools involving in this research. From this activity, the following conclusions can be drawn: (1) it is very important to start the learning with contextual problem, to make the students understand more about the benefit of mathematic learning, (2) the main activity of learning should be started by giving the students the discretion to reason and to solve the problem using the knowledge they have, thereby the learning is more meaningful to the students because the students construct their own knowledge, (3) the appropriate media choice highly supports the successful learning, in this case Excel ${ }^{\mathrm{TM}}$ utilization to process and to present the result of data analysis, (4) the students' IT skills (e.g. video/poster/social media) can be used to improve their communicating skill and positive character development, (5) the teacher should actually serve as a facilitator, focusing on the students' activity to make them independent and creative, (6) in the closing activity, the teacher should give feedback and reinforcement, and emphasize on what the students can develop by learning this material.

Considering the conclusion above, the authors recommend other researchers to take the following actions into account. First, vary the contextual problem design with open-ended questions, thus, the students can determine their own way of solving the problem. This design allows for the varying solution corresponding to the students' experience and creativity. Second, in the data collection process, the students should attempt to make an experiment related to energy efficiency, so that the learning process will be more meaningful and impacts on the change of energy efficiency habit.

\section{References}

Afrial, \& Rohmah, M. A. (2014). Using mathematics software and internet access for teaching in mathematics. Paper presented on the $3^{\text {rd }}$ International Symposium on Mathematics Education Innovation Joint Conference with $19^{\text {th }}$ ATCM, Sendimat, and $1^{\text {st }}$ ISIMMED.

Ishii, S. (2016). Toward enhancing energy efficiency in the APEC region. Paper presented at the $10^{\text {th }}$ APEC-Tsukuba International Conference: Innovation of Mathematics Education through Lesson Study Challenges to Energy Efficiency on STEM and Cross-Border Education. Tokyo: Natural Resources and Energy Research, International Affairs Division, Agency for Natural Resources and Energy, Ministry of Economy, Trade and Industry.

Kilpatrick, J., Swafford, J., \& Findell, B. (2001). Adding it up: Helping children learn mathematics. Washington, DC: National Academy Press.

National Council of Teachers of Mathematics (NCTM). (2009). Focus in high schools mathematics: Reasoning and sense making. Reston, Va.: NCTM. 
National Council of Teachers of Mathematics (NCTM). 2000. Principles and standards for schools mathematics. Reston, Va.: NCTM.

Wang, H., Moore, T., Roehrig, G., \& Park, M. (2011). STEM integration: Teacher perceptions and practice. Journal of Pre-College Engineering Education Research, 1(2), 1-13. 